\title{
Spatiotemporal features of farmland scaling and the mechanisms that underlie these changes within the Three Gorges Reservoir Area
}

\author{
LIANG Xinyuan", "LI Yangbing ${ }^{1,2}$ \\ 1. School of Geography and Tourism, Chongqing Normal University, Chongqing 401331, China; \\ 2. Key Laboratory of Surface Process and Environment Remote Sensing in the Three Gorges Reservoir Area, \\ Chongqing 401331, China
}

\begin{abstract}
Discussions regarding the functional transformation of agricultural utilization and the mechanisms that underlie these changes within the Three Gorges Reservoir Area (TGRA) reflect variations in the relationship between people and their environment in China's central and westerns part, an area of mountains and reservoirs. A clear understanding of these changes also provides the scientific basis for the development of multi-functional agriculture in typical mountainous areas. Five counties were selected for analysis in this study from the hinterland of the TGRA; we analyzed changes in farmland scaling and corresponding underlying mechanisms by defining the concepts of "Scaling Farmland" (SF) and by using the software packages ArcGIS10.2, SPSS, and Geographical Detectors. The results of this analysis show that sources of increased SF have mainly comprised cultivated and shrub land. Indeed, with the exception of some alpine off-season vegetables, SF growth has mainly occurred in low altitude areas and in places where the slope is less than $30^{\circ}$. We also show that spatial changes in various SF types have also been substantially different, but in all cases are closely related to road and township administrative centers. Natural factors at the patch level, including elevation and slope, have contributed significantly to SF, while at the township level, underlying socioeconomic and humanistic factors have tended to include road traffic and agricultural population density. In contrast, at the regional level, underlying driving forces within each have tended to be more significant than overall study area scale. We show that while changes in, and the development of, SF have been driven by numerous factors, agricultural policies have always been amongst the most important. The results clearly elucidate general land use transformation patterns within the mountain regions of western China.
\end{abstract}

Keywords: Three Gorges Reservoir Area; functional transformation of agricultural land; scaling farmland; spatiotemporal features; underlying driving forces

Received: 2018-06-14 Accepted: 2018-08-18

Foundation: Key Basic Science and Cutting Edge Technology Research Plan of Chongqing, No.cstc2015jcyjBX0128; National Natural Science Foundation of China, No.41261045; Chongqing Normal University Graduate Student Research Innovation Project, No.YKC18033

Author: Liang Xinyuan (1996-), Master, specialized in soil and water conservation and land use.

E-mail: liang_xiny@foxmail.com

"Corresponding author: Li Yangbing (1968-), PhD and Professor, specialized in land use and ecological process. E-mail: li-yapin@sohu.com 


\section{Introduction}

As human societies have developed over time, land use has also tended to undergo transitions from prehistoric forests and other natural ecosystems through the various stages of territory reclamation, livelihood-based agriculture, gradual intensification, and almost complete utilization (Defries et al., 2004; Foley, 2005). Land use intensification is an inevitable choice for humans given the multiple pressures of food security, economic development, and ecological protection (Lambin and Meyfroidt, 2011). This means that in order to guarantee human survival, cultivated land is likely to have also experienced a shift from rapid reduction, fragmentation and quality degradation through to stabilization, growth recovery, intensification, and multi-functionality (Liu et al., 2014).

In order to achieve agricultural modernization, countries around the world have gradually come to the realization that the fragmented management of rural land acts as an unfavorable factor that holds back agricultural development (Dai et al., 2015; Dong and Tang, 2015). Low agricultural output efficiency values in such situations have tended to compel governments to take economic or political measures to promote the large-scale operation of agricultural land. The development of farmland scale management therefore depends on levels of local economic development (Driscoll and Kraay, 1998); the concept of "Scaling Farmland"(SF) can therefore be regarded as the inevitable result of farmland scale management. At the same time, however, current research on large-scale farmland areas tends to be mainly focused on management types, their appropriateness, and the relationship between labor force and productivity (Tang and Zeng, 2014).

Current agricultural land scale within China falls far below the optimal per capita operational level. This means that agricultural land concentration is an important variable that can be assessed to improve labor productivity (Abro et al., 2014). At the same time, significant regional and individual differences are also seen in farmland scale management willingness (Niroula and Thapa, 2005); the suitable land management scale for single farmer households in the municipality of Chongqing, for example, falls between 0.33 ha and 1.19 ha, and the functional solution for measuring the appropriate size of a single land parcel is 0.90 ha (Yang et al., 2009). A number of relevant studies in this field have suggested that farmland scale is a common indicator of socioeconomic changes in rural areas, while varying national or local farming systems as well as policies and legislative changes can all lead to different interpretations of this concept (Moran, 1997). Agricultural land size expansion is therefore a key variable that should be taken into account to mitigate farmland abandonment and increase incomes (Tan et al., 2013). In this context, market competitiveness in terms of the agricultural value chain (Dannenberg and Kuemmerle, 2010) as well as policies and the labor force will all exert differential impacts on the scale and expansion of this land use type (Bartolini and Viaggi, 2013). Agricultural environmental measures will also lead to variation in farmland across different scales (İlkay and Štefan, 2015). All of these factors mean that SF distribution and change can be used to guide the direction of regional agricultural development, while the heterogeneity of regional conditions will also cause differential evolution of this variable. Existing research in this area has mainly focused on the function and impact mechanisms of farmland scale management; few analyses of SF spatiotemporal characteristics have been performed within typical regions. 
Growth in SF influences regional agricultural vitality, technological change, and the development of commercialization in different ways (Jayne et al., 2011). At the same time, land yield increases across China have also been closely related to the growth of this variable (Wang et al., 2015); this means that assessments of cultivated land natural conditions and the spatial resource endowments of small-scale areas can be used to overcome the shortcomings inherent to the disjunction between current research on land scale operations and geographical space. These approaches also provide the basis for a region to properly undertake appropriate scale operations and determine the intensive utilization of production space (Long et al., 2010). The hinterland of the Three Gorges Reservoir Area (TGRA) is defined as the Three Gorges resettlement area and is ecologically vulnerable (Meng et al., 2010); this region is dominated by mountains and hills and so farming conditions are harsh. Impoundment of the Three Gorges Dam also inundated large land areas within this region and had a significant impact on the development of agriculture and the rural economy. This has led to a sharp decline in cultivated land resources and an increase in non-agricultural construction land; as these trends have been unbalanced, conversion of land use types within the reservoir area has been promoted and has further exacerbated contradictions between humans and natural resources (Shao et al., 2018). These factors have also created new opportunities for the intensive use of land resources within the TGRA. The concept of "Scaling Farmland" (SF) is therefore defined in this study as typical of cultivated land functional transformation. Agricultural land use within the TGRA is then used as an example to discuss spatiotemporal changes and the driving forces underlying SF given the influence of various factors subsequent to impoundment of the Three Gorges Dam. The overarching goal of this analysis is to determine the nature of the changes seen in rural areas as well as the relationship between people and the environment in central and western regions, mountainous areas, and the TGRA. The results of this study therefore provide a clear scientific basis that can be used to guide the direction of agricultural development and multi-functional transformation in the mountainous areas of China.

\section{Study area}

The study area for this research is located in the center of the TGRA and encompasses a total area of approximately $18,729 \mathrm{~km}^{2}$ (Figure 1). This zone occupies more than half of the ecological conservation area of northeastern Chongqing, and includes the central and western regions of the Yangtze River Basin as well as the junction between three major regions of southwestern, northwestern, and central China. The sites selected for study comprise five districts and counties, namely, Kaizhou District as well as Wushan, Yunyang, Fengjie, and Wuxi counties, all of which exhibit significant differences in their levels of economic development. Terrain trends within the study area range from high in the northeast to low in the southwest, and encompass a complex set of conditions and various landform types. Climate across the study area is subtropical and humid monsoonal and includes extensive forest land coverage, severe sloping farmland reclamation, and fragile ecological environments. This region is characterized by the most serious levels of water and soil loss within the TGRA. 


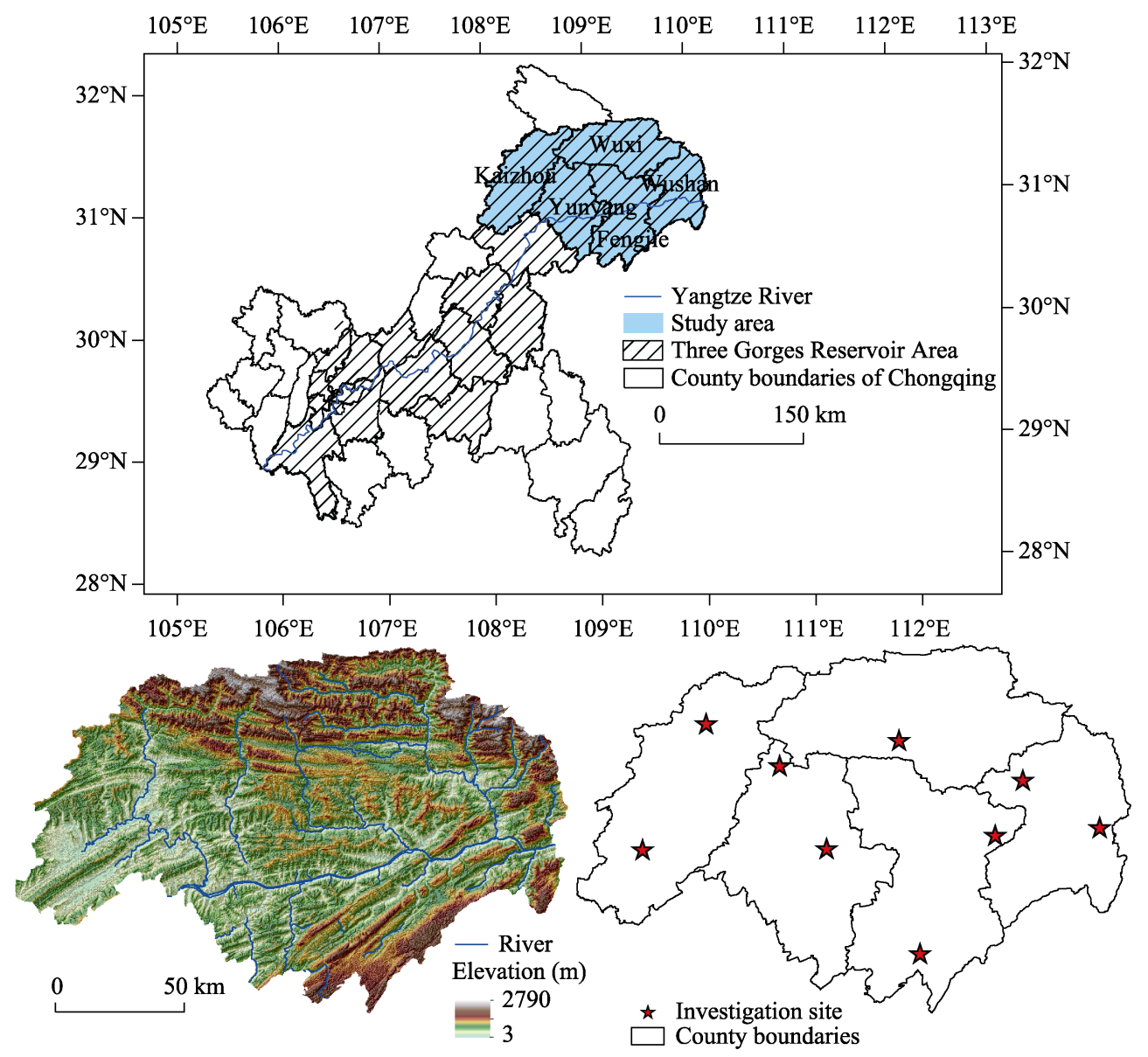

Figure 1 Location, topography, and spatial distribution of sites studied in the Three Gorges Reservoir Area

\section{Materials and methods}

\subsection{Definition and identification of scaling farmland}

Farmers have tended to adjust planting directions in light of land use transformations both to meet their own economic needs and to organize the agricultural land consolidation so that usage can be scale intensive (Petit et al., 2011); this phenomenon illustrates the SF transition of traditional farmland. We therefore defined the concept of SF both internally and externally by referring to the qualitative expression of the concept of "agricultural system transition" (Amjath-Babu and Kaechele, 2015). In this context, externality implies the presence of a perfect road system and complete infrastructure within a cultivated area; the dominant crops planted in such a region will therefore be non-food varieties with higher economic utility, and their layout will be arranged neatly with obvious traces of artificial planning. The opposite, internality, is therefore embodied by intensive agricultural land use that is distinct from conventional intensive utilization and is mainly driven by economic profit differentiation factors such as the economic behavior of farmers (or enterprises) and ecological construction policies put in place to promote the transformation of traditional agricultural land into multi-functional "Economic Ecotypes". This form of land use meets the requirements of modern agricultural construction (Table 1). 
Table 1 SF identification standards

\begin{tabular}{|c|c|c|c|}
\hline SF types & Identification standard & Data sources & Interpretation sign \\
\hline $\begin{array}{l}\text { Economic } \\
\text { fruit forest } \\
\text { land }\end{array}$ & $\begin{array}{l}\text { Neatly arranged in rows, concentrated } \\
\text { and contiguous, distinct individual, ob- } \\
\text { vious traces of artificial cultivation }\end{array}$ & $\begin{array}{l}\text { CNES Astrium } \\
\text { Quick Bird } \\
(0.51 \text { m resolution })\end{array}$ & \\
\hline $\begin{array}{l}\text { Vegetable } \\
\text { land }\end{array}$ & $\begin{array}{l}\text { Neatly arranged in rows and blocks, with } \\
\text { complete road facilities, most of them are } \\
\text { presented in greenhouses. }\end{array}$ & & \\
\hline Tea garden & $\begin{array}{l}\text { Stripe distribution, large band width and } \\
\text { ladder-like appearance, wide range of } \\
\text { extension }\end{array}$ & & \\
\hline $\begin{array}{l}\text { Tobacco } \\
\text { land }\end{array}$ & $\begin{array}{l}\text { Stripe distribution, clear image lines, } \\
\text { slightly narrower stripes }\end{array}$ & & \\
\hline $\begin{array}{l}\text { Medicinal } \\
\text { material land }\end{array}$ & $\begin{array}{l}\text { Block distribution, neatly arranged. The } \\
\text { imaging shows slightly stereoscopic and } \\
\text { the overall height of the crop is moderate }\end{array}$ & & \\
\hline
\end{tabular}

In this context, SF scale is mainly determined on the basis of relevant research regarding the moderate-scale management of domestic farmland and family farms both within China and around the world (Yang et al., 2016). It has proved difficult, however, to implement farmland consolidation within the TGRA because of complex terrain conditions and a low level of agricultural mechanization, especially in mountainous areas. The main SF component within this region has also tended to become more diversified, including the dominant behavior of farmer households, enterprises, and the government. An area of 2 ha was therefore used here as the basic SF standard via field inspections (Xu and Yin, 2010), while 0.47 ha was utilized for the scale of this variable given the behavior of farmers in accordance with the optimum scale of family farm, as suggested by Herdt and Mandac (1981). In light of the time attributes inherent to the agglomeration characteristics of SF as well as remote sensing (RS) data resolution, a series of subjective interpretations were therefore performed based on the proximity and aggregation trends of fragmentized patches at the landscape level via human-computer interactions. Thus, SF patches with areas less than 0.47 ha accounted for $15.84 \%$ and $12.45 \%$ of the total were used in 2009 and 2016 , respectively. Errors due to individual subjective behaviors in judging agglomerations remained negligible in this analysis due to their small proportions. These approaches mean that SF comprises a multi-functional agricultural set of large-scale non-grain crops that either exhibit agglomeration trends or have been used intensively by farmers, enterprises, or government under the influence of economic behaviors and ecological policies. 


\subsection{Data sources}

The spatial data utilized here includes RS images captured by the Chongqing Quick Bird satellite in 2016; these images have a $0.51 \mathrm{~m}$ resolution while those captured by the China-Brazil Earth Resources satellite have a resolution of $2.5 \mathrm{~m}$ across the TGRA hinterland and were captured in 2009. Our acquisition of township-level administrative divisions was mainly based on the adjustments of these categories within districts and counties in recent years, including a total of 165 comprising townships as well as towns and streets. The statistical data used in this study were extracted from the 2015 China County Statistical Yearbook (Township Volume) as well as the 2016 statistical yearbook for each district and county.

We divided SF into five categories for analysis including economic fruit forest land, vegetable land, tea gardens, tobacco land, and medicinal material land (Figure 2) based on the GDPJ01-2013 Geographical National Conditions Survey Contents and Indicators. Thus, on the basis of the interpretation marks established in our field survey (Figure 1), SF vector patches were obtained using the software ArcGIS10.2 and used to interpret RS images via human-computer interactions. Interpretation accuracies for the five SF types were 96.1\%, $93.5 \%, 89.7 \%, 91.4 \%$, and $87.7 \%$ after field verification, respectively.

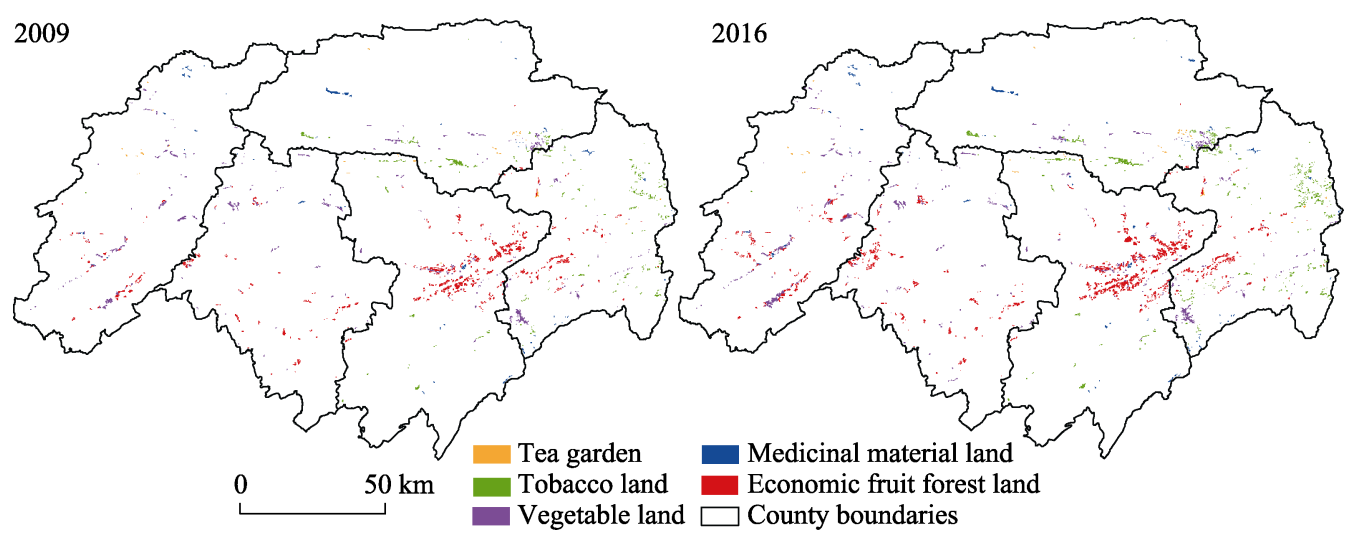

Figure 2 The spatial distribution of various SF types in the Three Gorges Reservoir Area in 2009 and 2016

\subsection{Research methods}

\subsubsection{Indicator selection}

A complete indicator system was established for this analysis based on related research (Guo et al., 2015; Su et al., 2016), encompassing nature, socioeconomic, and humanity-based factors to reveal the underlying factors influencing SF growth. These factors were analyzed in detail at both patch and township levels (Figure 3); eight indicators were selected as explanatory variables at the patch level, while ten were selected at the township level. Demographic data including urbanization rates have often been analyzed as socioeconomic factors in previous land-use related studies; however, since the mutual relationship between population levels and economic distribution within the TGRA is constantly changing geospatially (Zhou et al., 2011) due to the influence of mountainous location conditions and the special nature of resettlement projects, population-related data were summarized as humanistic factors in this analysis. All indicator data attributes were therefore considered to be continuous 
raster types for this study and were re-sampled at a resolution of $500 \mathrm{~m}$ to create a Geographic Information System (GIS) database. Combined with the actual scope of the study area after repeated simulations, a resolution of $500 \mathrm{~m}$ accurately reflects the essential characteristics of most dependent variables.

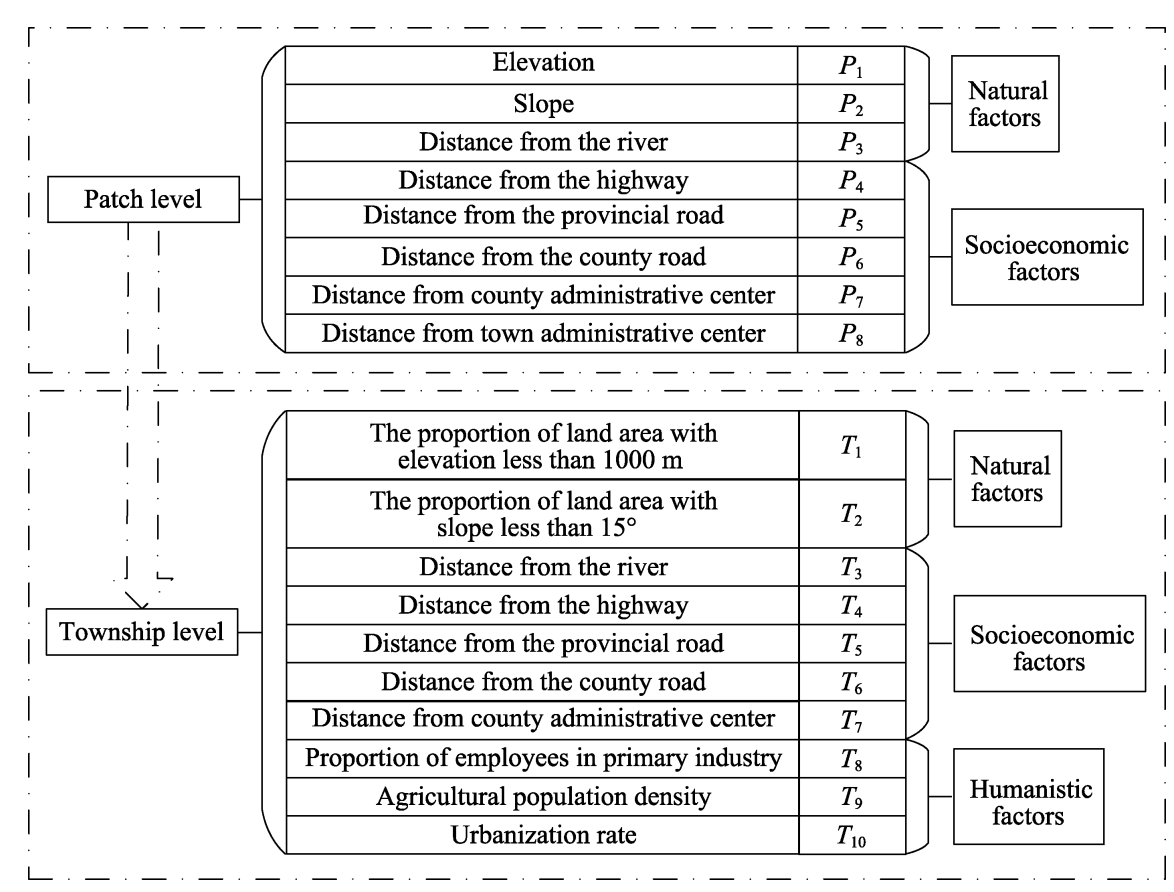

Figure 3 SF driving index

\subsubsection{Multiple logistic regression model}

A logistic model is a regression expression established on the basis of two, or more, response variable categories such that independent variables can either be qualitative or quantitative data hypotheses. An increase (or not) in SF was considered here as two variables, and a binary logistic regression model was utilized (Wu et al., 2010), as follows:

$$
f(x)=\frac{e^{x}}{1+e^{x}}
$$

Thus, according to the definition of the expected discrete random variable value, $p$ was used to represent the probability $y=1$ while the independent variable was $x$. It therefore follows that:

$$
f(p)=\frac{e^{p}}{1+e^{p}}=\frac{e^{\left(a+b_{1} x_{1}+b_{2} x_{2}+\cdots+b_{n} x_{n}\right)}}{1+e^{\left(a+b_{1} x_{1}+b_{2} x_{2}+\cdots+b_{n} x_{n}\right)}}
$$

As change in the function $f(p)$ for $x$ is insensitive and slow in the vicinity of $f(p)=0$ or $f(p)$ $=1$, and the degree of nonlinearity is high, a logistic transformation of $f(p)$ can be introduced, as follows:

$$
\log i t(p)=\log (p / 1-p)=a+b_{1} x_{1}+b_{2} x_{2}+\cdots+b_{n} x_{n}
$$

The probability of $p$ can therefore be calculated, as follows:

$$
p=\frac{e^{\left(a+b_{1} x_{1}+b_{2} x_{2}+\cdots+b_{n} x_{n}\right)}}{1+e^{\left(a+b_{1} x_{1}+b_{2} x_{2}+\cdots+b_{n} x_{n}\right)}}
$$


Analyzing the natural and economic factors influencing the growth of the five SF types considered in this study (i.e., economic fruit forest land, vegetable land, tea gardens, tobacco land, and medicinal material land), a series of primary and secondary relationships were determined according to the contribution of each to overall growth. The purpose of this analysis was to predict the probability of SF growth in each case based on impact factors corresponding to patch and township.

\subsubsection{Geo-detector implementation}

The spatial distributions of geographic entities and phenomena are influenced by a variety of natural and socioeconomic factors. This means that an analysis of formation mechanisms is of considerable significance if we are to determine the spatial distribution characteristics that underlie geographic phenomena (Wang et al., 2016). The use of a geo-detector in this context was proposed by Wang and $\mathrm{Hu}$ (2012) on the basis of spatial superposition technology and set theory, as follows:

$$
P_{D, H}=1-\frac{1}{N^{\prime} \sigma_{H}^{2}} \sum_{w=1}^{m} n_{D, w} \sigma_{H_{D, w}}^{2}
$$

In this expression, $P_{D, H}$ denotes the influence of an impact factor on newly-increased $\mathrm{SF}$, while $\sigma_{H}^{2}$ refers to variance in the number of newly-increased SF across the entire region, $\sigma_{H_{D, w}}^{2}$ is the variance in this factor in a second-level region $w$, and $N^{\prime}$ is the number of samples (i.e., $N^{\prime}=165$ ). Thus, $n_{D, w}$ denotes the number of samples in the second-level region $w$, and $m$ is the number of second-level regions (i.e., the number of influential factors in natural clustering and zoning, $0 \leqslant w \leqslant m$ ); this means that when $0 \leqslant P_{D, H} \leqslant 1$ and $P_{D, H}=0$, the spatial distribution of newly-increased SF is not driven by a particular impact factor. In other words, the greater the value of $P_{D, H}$, the greater the influence of zoning factors on newly-increased SF; this variable can therefore be used to explain the spatial differentiation characteristics of newly-increased SF with a higher degree of confidence.

A geo-detector algorithm for categorical data is superior to one for continuous data (Wang et al., 2010), and so K-means clustering of continuity detection factors was initially performed using the software SPSS, divided into 1, 2, 3, 4, 5, 6, and 7 categories. All the factors we used were based on 2016 status data, and there is no corresponding relationship between their level of clustering and the actual influence of detection in each case. The spatial distribution of each detector category is illustrated in Figure 4, and a-j correspond to the township level influencing factors $\mathrm{T}_{1}-\mathrm{T}_{10}$.

\section{Results and analysis}

\subsection{SF spatiotemporal variation}

\subsubsection{SF temporal changes}

The data collated here reveal that the main types of land use within the study area in 2009 comprised forested and cultivated land (Figure 5). Results show that SF growth between 2009 and 2016 was basically derived from dry land and paddy fields, and that the transfer volume from other land types to SF remained very small. The main transfer sources generating economic fruit forest land comprised dry land (61.67\%) and paddy fields (16.76\%). As a crop planted in either dry or irrigated land, scaling processes leading to vegetable land 
comprised either transfer of the dry land $(44.07 \%)$ or paddy fields $(27.34 \%)$, while the main source of tea gardens was also from dry land (64.12\%) and the total amount of shrub land transfer increased to $17.85 \%$. Tobacco land is also a dryland crop and transfer into this type

(a)
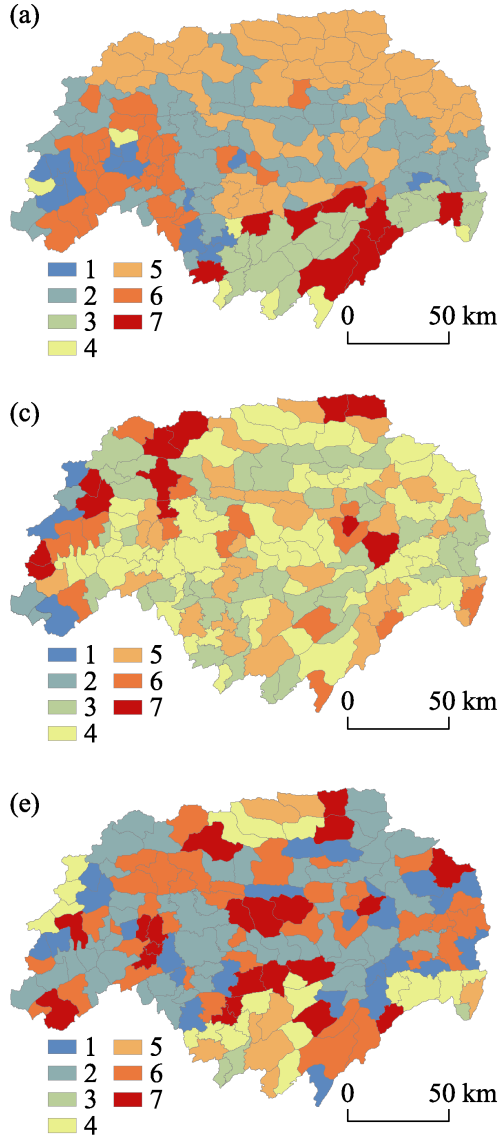

(g)
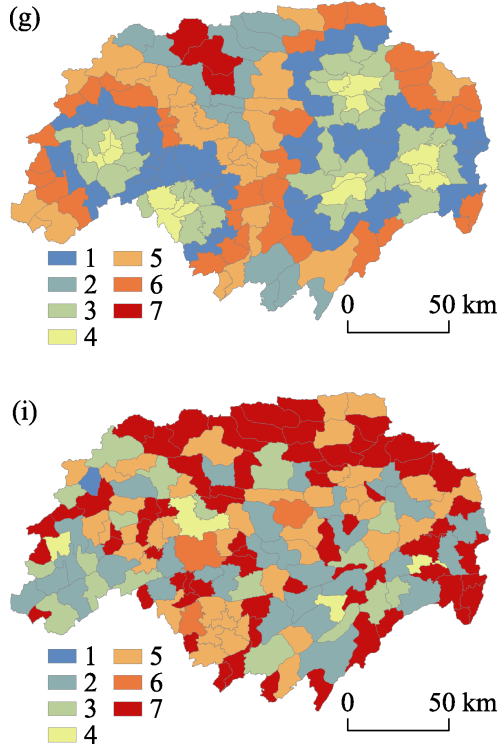

(b)

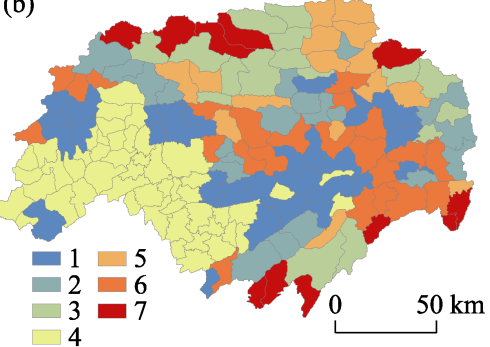

(d)
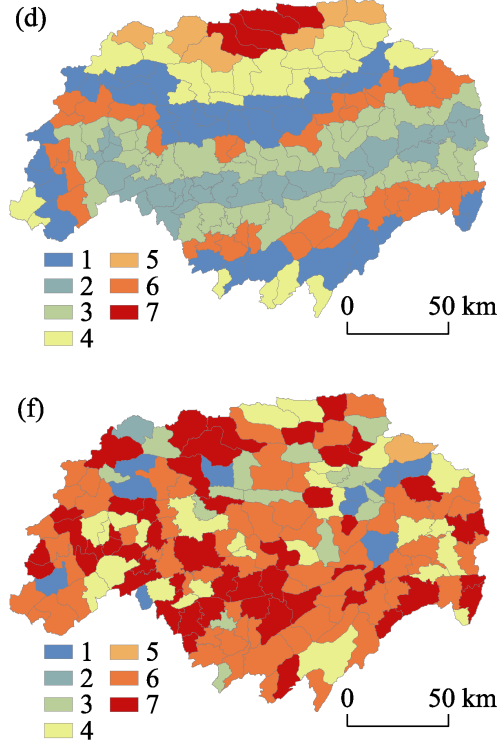

(h)

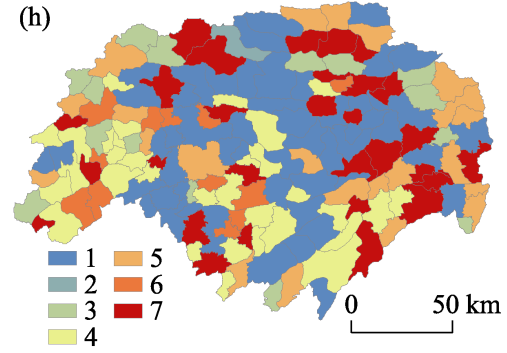

(j)

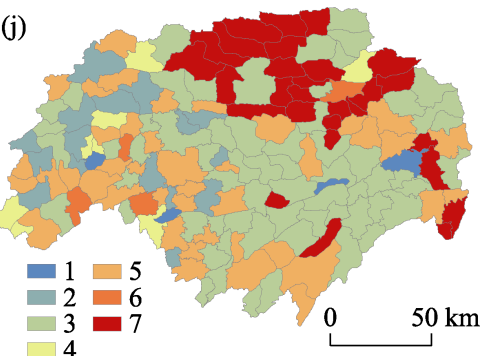

Figure 4 The spatial distribution of classified geographic detection factors in the Three Gorges Reservoir Area 

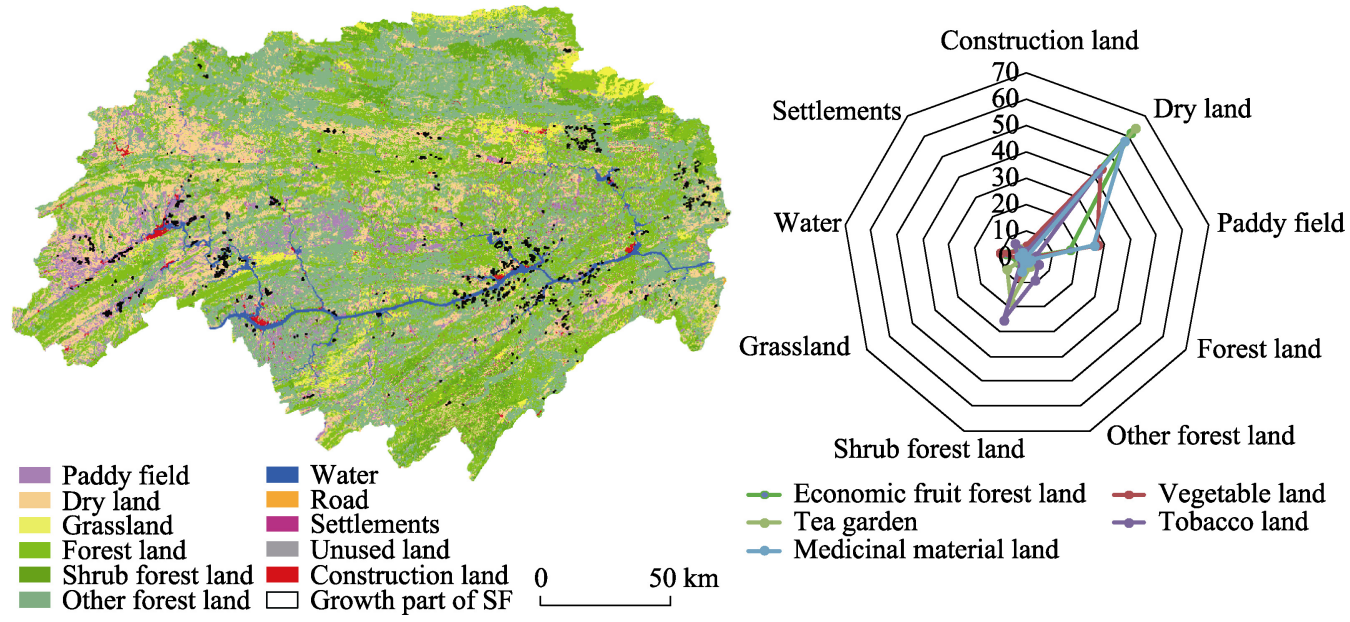

Figure 5 Land use types in 2009 and sources of SF in the Three Gorges Reservoir Area in 2016

mainly comprised shrub land $(25.37 \%)$ with the exception of a large proportion of dry land $(41.79 \%)$, while the main transfer sources for medicinal material land were dryland $(57.74 \%)$ and paddy fields $(26.01 \%)$.

\subsubsection{Spatial SF change processes}

The results presented in Figure 6 reveal spatial changes in SF growth. These data show that growth in economic fruit forest land over the time period of this analysis was mainly concentrated in areas with elevations less than $800 \mathrm{~m}$ and slopes between $15^{\circ}$ and $25^{\circ}$. Growth in this land use type is negatively related to distances from rivers and highways as well as county and provincial roads; indeed, economic fruit forest land area increased at a uniform rate within a range of $10 \mathrm{~km}$ to administrative town centers.

Growth in vegetable land has been mainly concentrated in areas at elevations less than $800 \mathrm{~m}$, and mostly within a range of slopes less than $10^{\circ}$; this relationship is significantly negatively correlated with slope. As this industry is market-oriented, the resource integration process of economic fruit forests and vegetables has generally tended to be concentrated in township regions and the transition from low-level to high-level markets has gradually been achieved via a "bottom-up" market-oriented law.

Data show that the growth of tea gardens across the study area has mainly been distributed within a range of elevations between $400 \mathrm{~m}$ and $1200 \mathrm{~m}$, slopes between $10^{\circ}$ and $32^{\circ}$, and at distances between $2 \mathrm{~km}$ and $10 \mathrm{~km}$ from town administrative centers. Maximum values in this case were attained at $6 \mathrm{~km}$ distances from rivers and $7 \mathrm{~km}$ distances from highways; indeed, tea garden growth has tended to exhibit jumps in concert with increasing distances from provincial roads while the opposite has been seen with respect to county roads. These trends suggest that the production and marketing of tea in regions has mainly been focused on district and county units, although a holistic distribution pattern was not clear due to the small sample size of this study.

Growth in tobacco land across the study area has mainly been distributed within a range of elevations between $400 \mathrm{~m}$ and $1,600 \mathrm{~m}$, distances from rivers less than $8 \mathrm{~km}$, and slopes less than $32^{\circ}$; the distribution ratio in this case is negatively correlated with increasing slope as well as distance from provincial and county roads. Data show that growth in tobacco land has been evenly distributed within a range between $13 \mathrm{~km}$ and $9 \mathrm{~km}$ from county adminis- 

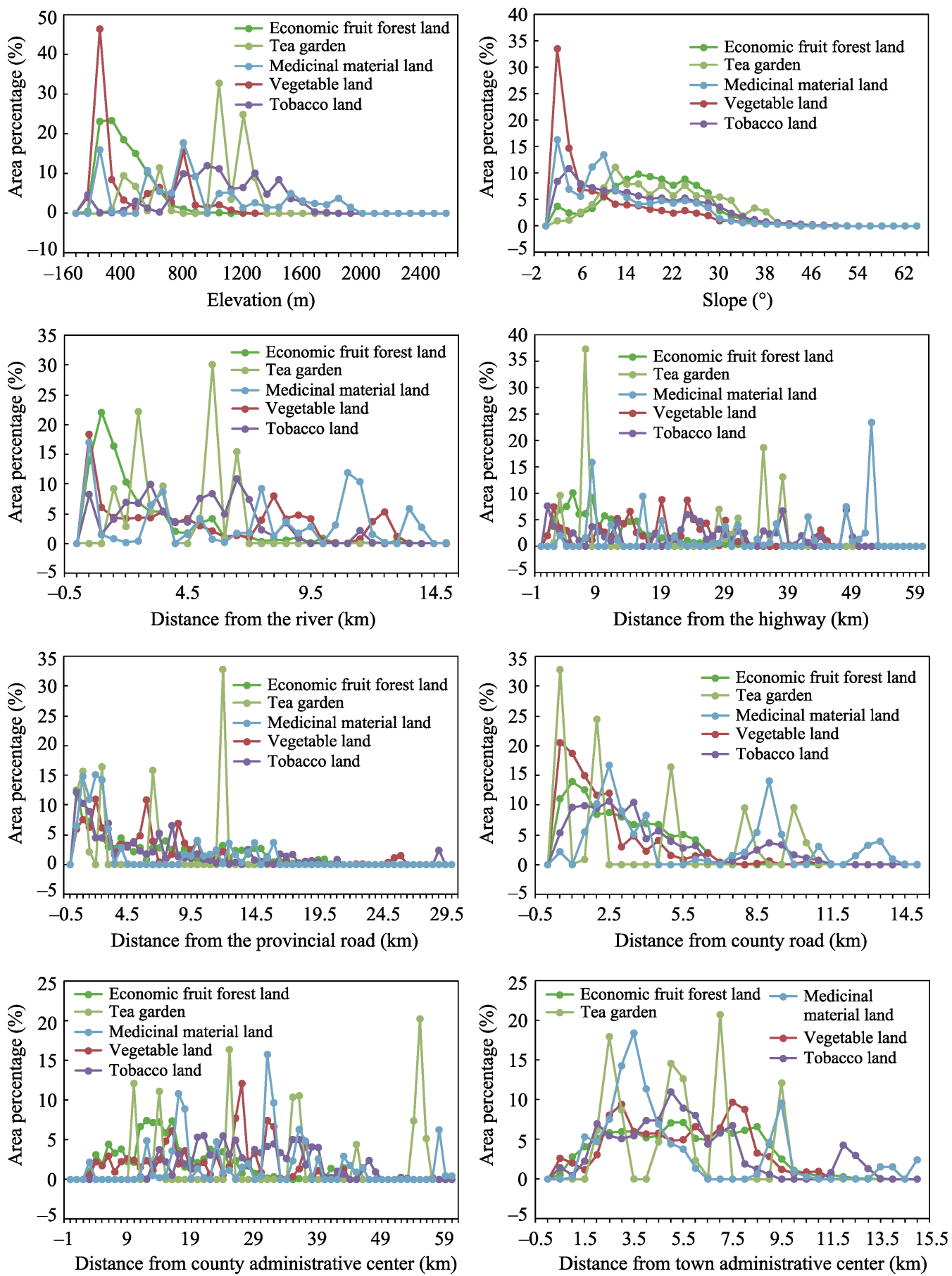

Figure 6 Spatial variations in SF across the Three Gorges Reservoir Area

(The area percentage shown here represents the ratio of SF area change while the buffers account for total SF area change throughout the study period)

trative centers; changes in this land use type have conformed to a trend of initial increase followed by subsequent decrease with distance from town administrative centers.

Growth in medicinal material land has tended to be distributed within areas with elevations less than 2,000 m. Data show that this land use type initially increased and then de- 
creased in regions with slopes less than $30^{\circ}$ and have tended to be concentrated at distances less than $4 \mathrm{~km}$ from provincial roads. Changes in this land use type have also tended to initially increase and then decrease with distance from town administrative centers. As tobacco and medicinal materials both have high requirements for soil quality and are labor-oriented industries, underlying change laws have tended to be basically the same.

\subsection{Factors underlying changes in various SF types}

We utilized values of the Wald statistic output by the software SPSS as estimates for the regression coefficient. These indicate the relative weight of each explanatory variable in our model and can be used to evaluate the contribution of each to event prediction (Rgjr and Schneider, 2001). Data show that the most important factor influencing SF growth at the patch level (Figure 7) was $\mathrm{P}_{2}$ (slope) in all cases apart from economic fruit forest land. This is because the cultivation of economic fruit forests is generally carried out in low-altitude areas as this facilitates both planting and harvesting. Indeed, in order to improve water efficiency and control soil erosion, economic fruit forests also tend to be planted across large areas and encompass a wide range of slopes, while sources for vegetable land are dominated by areas with low slopes, including cultivated land. Tea gardens tend to be distributed on steep slopes and spatial structures similar to terraces for easy management. The law underlying the placement of tobacco and medicinal material land are also basically the same, as these types tend to be distributed on flat terrain with low slopes. The overall results of this analysis show that the contribution of all factors apart from slope are unobvious; the forces driving of natural factors were high when farmers grew SF, especially when harvest and ef-
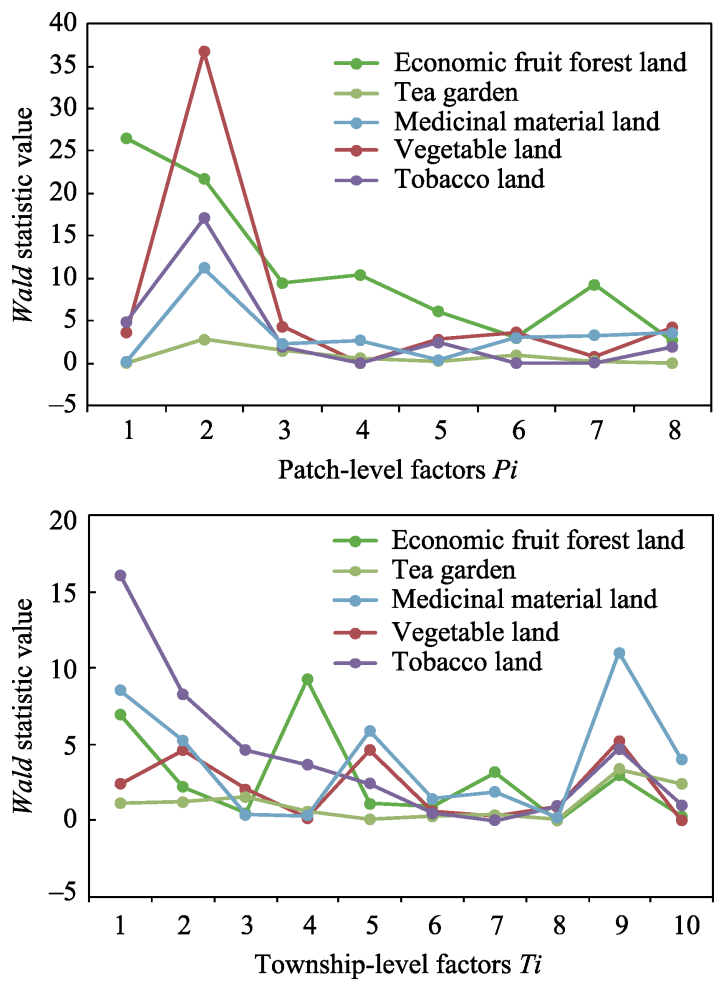

Figure 7 Values for the Wald statistic at different levels ficiency issues were taken into account. Most farmers do not attach importance to distance to market or the convenience of transportation.

The average contribution of township-level factors relative to patch level was slightly higher throughout the scope of this analysis, and all SF variables tended to be close to highways, provincial roads, and other regional connecting channels. This result shows that decision makers at this level pay more attention to the convenience of communicating with markets although natural variables still make a high relative contribution. $\mathrm{Hu}-$ manistic factors, such as agricultural population density, also exert a significant influence on tea garden and medicinal material land SF, related to the amount of labor demand. Data show that the development of SF from the perspective of farmers has tended to emphasize the advantages and disadvantages of natural 
planting conditions to a greater extent in order to achieve individual economic development. Decision makers at the township level plan the overall allocation of labor resources and infrastructure construction via government regulations and supplement the needs of local economic development via SF benefits while at the same time promoting its development.

\subsection{Factors driving SF changes across the study area}

Values for $P_{D, H}$ that reflect the ability of each detection factor $T_{i}$ (i.e., identical to township-level influencing factors) affecting the SF growth process were calculated using a geo-detector (Figure 8 and Table 2). Results show that the influence of each detection factor on the entire scope of the study area remained extremely weak while at the same time exerting a strong influence on low-level space evaluation units (districts and counties).

Table 2 Influence of detection factors

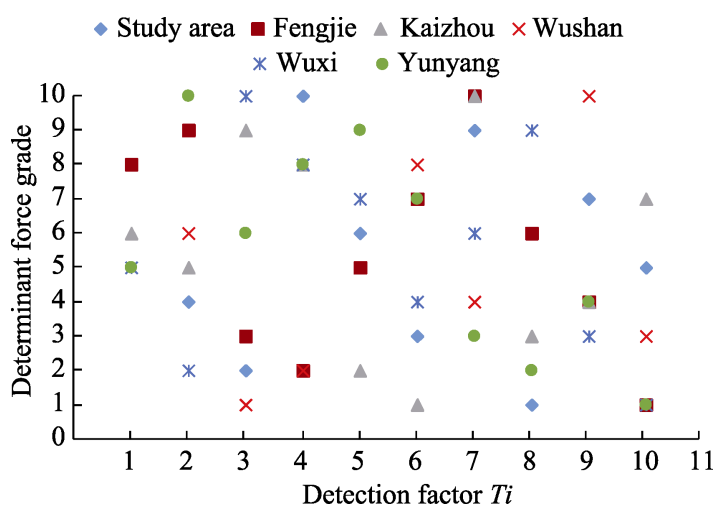

Figure 8 Detection factor determination levels

\begin{tabular}{ccccccc}
\hline Detection factors & Study area & Fengjie & Kaizhou & Wushan & Wuxi & Yunyang \\
\hline$T_{1}$ & 0.05 & 0.25 & 0.14 & 0.14 & 0.13 & 0.11 \\
$T_{2}$ & 0.03 & 0.28 & 0.14 & 0.18 & 0.01 & 0.39 \\
$T_{3}$ & 0.02 & 0.12 & 0.22 & 0.06 & 0.49 & 0.16 \\
$T_{4}$ & 0.07 & 0.11 & 0.17 & 0.08 & 0.28 & 0.24 \\
$T_{5}$ & 0.03 & 0.17 & 0.06 & 0.20 & 0.26 & 0.35 \\
$T_{6}$ & 0.02 & 0.17 & 0.04 & 0.23 & 0.09 & 0.20 \\
$T_{7}$ & 0.05 & 0.32 & 0.26 & 0.10 & 0.21 & 0.09 \\
$T_{8}$ & 0.01 & 0.17 & 0.07 & 0.25 & 0.34 & 0.08 \\
$T_{9}$ & 0.04 & 0.15 & 0.09 & 0.35 & 0.08 & 0.09 \\
$T_{10}$ & 0.03 & 0.02 & 0.15 & 0.09 & 0.01 & 0.05 \\
\hline
\end{tabular}

(1) Results for Fengjie County reveal that this area has been vigorously developing a navel orange industry in recent years, and so the direction of production and marketing has generally been headed at the county level and has subsequently expanded outwards. The development of this industry is therefore closely related to the distance from county centers and roads. The major SF in Fengjie County was economic fruit forest land, and the complexity of planting conditions led to a strong dependence on natural factors.

(2) The growth of SF in Kaizhou District was reliant on the distance from the county center and the river because of the vigorous development of the vegetable industry. Increases in the urbanization rate were accompanied by improvements in quality of life which themselves promoted SF development.

(3) Changes in SF in Wushan County were dominated by tobacco land for which planting conditions are highly dependent on labor. These changes are therefore closely related to humanistic factors including agricultural population density while convenient transportation satisfied the living requirements of the labor force.

(4) Wuxi County has tended to lag behind the rest of the study area in terms of economic development, with relative disadvantages in terms of both infrastructure construction and natural conditions. The total amount of SF was the smallest in this case and remains at a de- 
velopment stage; and most of them rely on rivers and other water source conditions, close to roads and county centers.

(5) Growth in SF within Yunyang County reveals a reduction in the force of humanistic factors. The SF planting type in this region is dominated by economic fruit forest land. As an important hub of the economic corridor along the Yangtze River within the TGRA, SF growth in Yunyang County is closely related to highways and roads.

\section{Discussion}

\subsection{The significance of SF distribution and changes}

The distribution of SF values basically extends from the bank of the Yangtze River to north and south in an axial direction, mainly in flat areas along the river valley. Data show that vegetable land tends to be distributed at slopes less than $10^{\circ}$, while economic fruit forest land and tea gardens are mainly distributed in areas with slopes between $10^{\circ}$ and $30^{\circ}$, and tobacco land and medicinal material land are distributed on land with slopes less than $30^{\circ}$. The results of this analysis show that all SF types are concentrated on land with elevations less than $1500 \mathrm{~m}$; indeed, most SF tends to have enhanced requirements for suitable altitude with the exception of a few crops requiring alpine cultivation environments. The type of SF across the field area tends to be dominated by economic fruit forest land close to roads and town administrative centers; this result indicates that development has gradually catered to the orientation of the market economy and has shifted from a single food supply function to modern multi-functional farmland. The formation of SF, including economic fruit forest land and tea gardens, will help improve soil conditions and ecological functions.

The results of our field surveys indicate that the development of SF, especially economic fruit forests, is based on intensive land use as a means to improve economic and ecological benefits. The transformation of most forest land to SF has therefore conformed to the principle of "using economic fruit forest instead", replacing former shrub land with economic fruit forests to increase economic efficiency while ensuring ecological benefits. Orchard development, however, does not fully guarantee regional ecological security; farmers clear grass and shrubs within economic fruit forest planting areas to render trees more intensive and to ensure economic benefits, a process which results in a large area of land exposure and affecting the ecological benefits of planted regions. Intercropping is therefore necessary to improve regional ecological benefits. Cultivated land functional transformation (Figure 9) has therefore promoted SF formation while the intensive planting conditions have improved the status of sloping farmland and reduced ecological risks. The distribution and changes in SF therefore represent farmland transitions, especially sloping land; the evolution of sloping farmland is closely related to the development of economic fruit forests while SF changes have determined the direction of regional agricultural transformation. This has provided guarantees for the sustainable development of modern agriculture and ecological security across the study area.

\subsection{Mechanisms driving policy responses to SF change}

In earlier work, You (2017) discussed the process of exploring dynamic changes in the agricultural landscape within Ningbo City, which revealed that economic transformations have influenced the agricultural landscape by influencing changes in land use patterns. Liu et al. (2016) had earlier shown that the changes in crop types and their spatial distribution within Zhangye City were mainly due to the advancement of economic development and urbaniza 


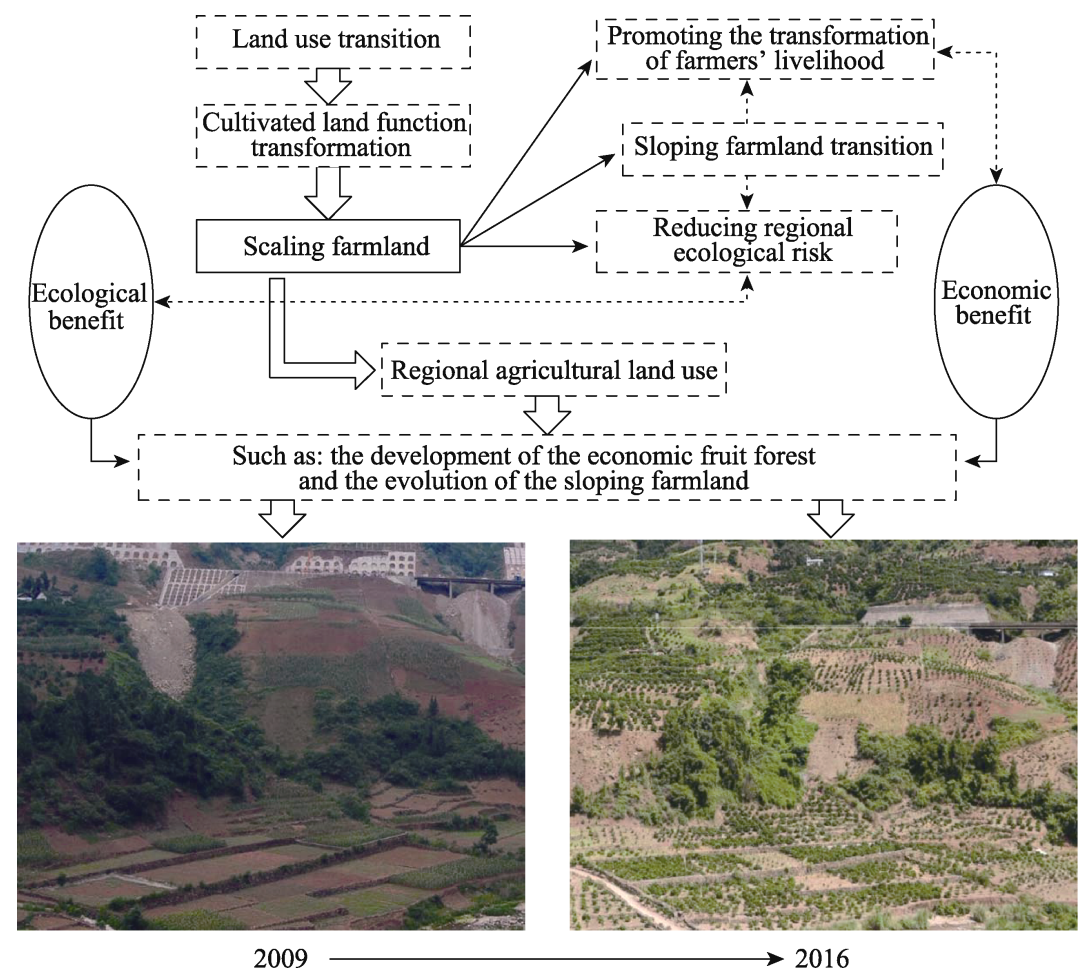

Figure 9 Regional agricultural land use transformations

tion. The development focus of SF will therefore differ at various stages of socioeconomic development. Our data show that the proportion of SF across our study area ranges from the largest-to-smallest in the order of Fengjie, Kaizhou, Wushan, Yunyang, and Wuxi; these subdivisions basically conform to the economic development level of each district and county.

Although SF is closely related to the level of socioeconomic development, it remains constrained by numerous other factors. At the patch level, individual interests of farmers are the main factors; at the township level, development direction of local government is the goal; while at the regional overall level, SF development is guided by national policies. SF development space generally tends occur in planting environments with superior natural conditions from the perspective of farmer households, while the role of natural and socioeconomic factors is slightly stronger than humanistic factors. Local governments promote the development of SF and effective agriculture enables the development of national policies which pay attention to the economic and ecological benefits of cultivated land transitions. The influences of socioeconomic and humanistic factors are therefore stronger than natural ones and the relationship between various drivers is complementary (Figure 10).

Implementation of Three Gorges Dam construction, water storage, and resettlement projects have successively enabled the economy to develop rapidly within the TGRA. Social changes under the market economic system, such as industrial restructuring and infrastructure construction, have accelerated the transformation of rural areas, while the massive movement of young laborers has also transformed the livelihoods of rural households. Additional factors such as the complex topography of mountainous terrain and the difficulty to integrate agricultural resources due to natural conditions have all promoted the intensive use of land in mountainous rural areas. The development of SF within the TGRA occurs at the 


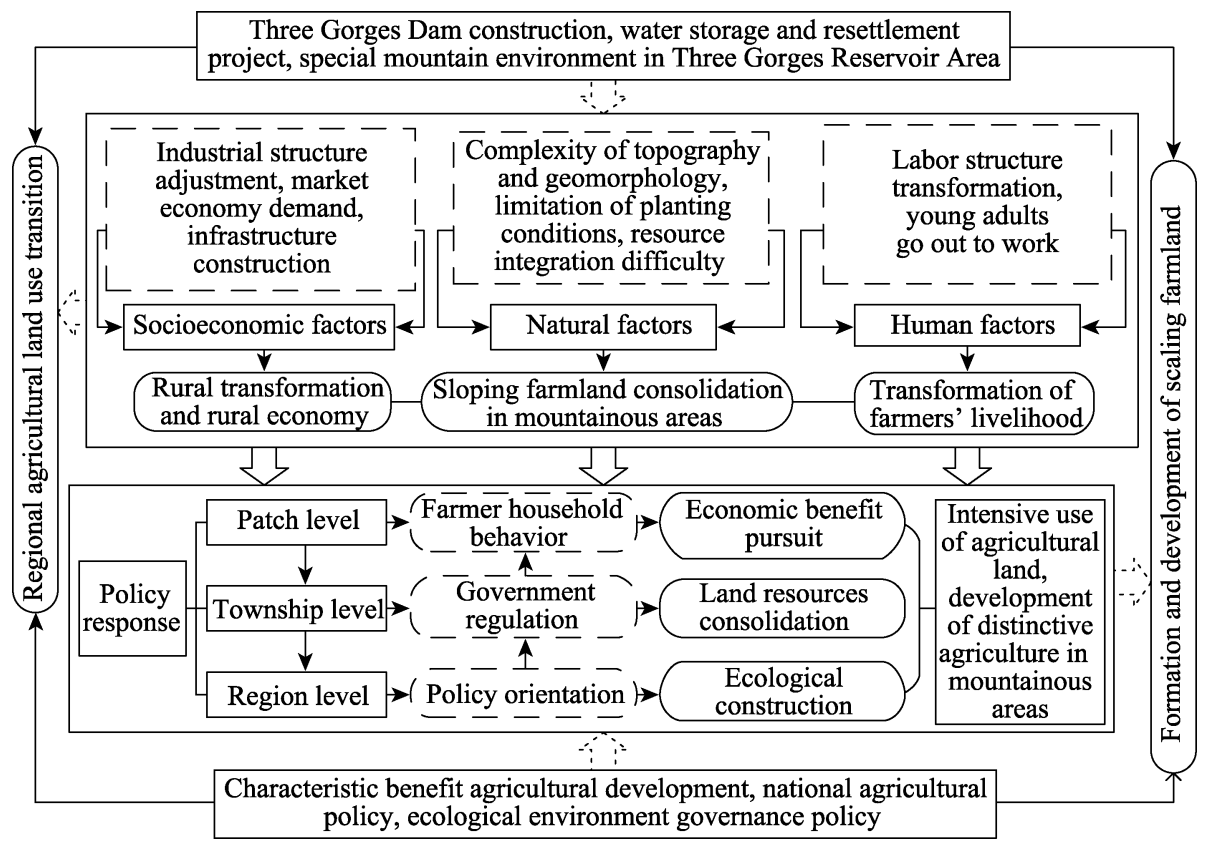

Figure 10 The mechanisms driving policy responses to SF change

intersection of the sloping farmland transition and policy requirements such as ecological governance in the mountainous rural areas. Varying levels of behavioral agents will therefore interact to promote the development of SF in different directions, but generally these are affected by the status of national agricultural development and government policy guidance. The effectiveness of policy tools must therefore address the complexities of ecology, economy, and society, as well as the personal decisions of local actors that lead to institutional change (Grashof-Bokdam et al., 2016). Agricultural policies will affect the focus of each driver; thus, discussion of the evolution of SF within the TGRA will help to ascertain the influence of various driving factors and aid decision makers to propose reasonable development policies for agricultural development under different environmental conditions.

\section{Conclusions}

The concept of SF is presented in this paper. Data reveal the processes of cultivated land functional transformation via analysis of the development and evolution of SF within the TGRA. Results show that:

(1) The distribution of SF values basically extends from the bank of the Yangtze River to the north and south in an axial direction, mainly in flat areas along the river valley. SF are concentrated on land with elevations less than $1500 \mathrm{~m}$ and slopes less than $30^{\circ}$; most SF tends to have enhanced requirements for suitable altitude with the exception of a few crops requiring alpine cultivation environments. The proportion of SF across our study area ranges from largest-to-smallest in the order Fengjie, Kaizhou, Wushan, Yunyang, and Wuxi; these subdivisions basically conform to the economic level of each district and county.

(2) SF represents the multi-functional development level of cultivated land utilization within this area, and large-scale exploitation of the economic fruit forest type in SF revealed the use patterns and ecological implications of the sloping farmland in the TGRA. This result therefore indicates that the direction of cultivated land functional transformation in the 
TGRA will continue to emphasize the win-win of economic and ecological functions. The functional transformation of cultivated land use in the TGRA conforms with Chinese agricultural social and ecological economic development policies and promotes the formation and development of SF. Changes in the spatiotemporal distribution of SF indirectly reflects the fact that future development trends will be oriented to meet market demand. The results of this study therefore elucidate general patterns in land use transformation in mountainous regions of western China.

(3) Our analysis of driving mechanisms at different scale levels reveals that natural factors contributed most to the growth of SF at the patch level, while at the township level, these changes were mainly driven by socioeconomic and humanistic factors. In contrast, at the regional level, driving factors of districts and counties were more significant than overall factors and were closely related to the direction of agricultural development such that each county combined its own development advantages with government policies. Analysis of these factors across three scales shows that there are certain intrinsic links that connect the individual behaviors of rural households, the regulation of lower-level government, and the orientation of national policies. Our ultimate goal is to develop characteristic and effective agriculture, to improve the ecological environment and the rural economy in the TGRA which will further accelerate SF formation.

(4) This study has a number of deficiencies, including the fact that SF is one product of cultivated land functional transformation. The true meaning of this variable is therefore not limited to just the five standards defined in this analysis, but also encompasses other multi-functional agricultural parks such as leisure and sightseeing agriculture. In order to facilitate analysis and expression, SF was nevertheless classified according to planting types in this analysis; we believe that the results of this study objectively reflect the status quo of agricultural functional transition across the TGRA study area.

\section{References}

Abro Z A, Alemu B A, Hanjra M A, 2014. Policies for agricultural productivity growth and poverty reduction in rural Ethiopia. World Development, 59(3): 461-474.

Amjath-Babu T S, Kaechele H, 2015. Agricultural system transitions in selected Indian states: What do the related indicators say about the underlying biodiversity changes and economic trade-offs? Ecological Indicators, 57: $171-181$.

Bartolini F, Viaggi D, 2013. The common agricultural policy and the determinants of changes in EU farm size. Land Use Policy, 31(2): 126-135.

Dai S Q, Wu B W, Wu S D et al., 2015. Priority research of hilly land consolidation based on land fragmentation and location condition: A case study of Songxi county, Fujian province. Journal of Guizhou Normal University (Natural Sciences), 33(4): 14-20. (in Chinese)

Dannenberg P, Kuemmerle T, 2010. Farm size and land use pattern changes in postsocialist Poland. Professional Geographer, 62(2): 197-210.

Defries R S, Asner G P, Houghton R A, 2004. Trade-offs in land-use decisions: Towards a framework for assessing multiple ecosystem responses to land-use change. Geophysical Monograph, 153: 1-9.

Driscoll J C, Kraay A C, 1998. Consistent covariance matrix estimation with spatially dependent panel data. Review of Economics and Statistics, 80(4): 549-560.

Dong X J, Tang H J, 2015. A review on the scale operation of farmland worldwide. Chinese Journal of Agricultural Resources and Regional Planning, 36(3): 62-71. (in Chinese)

Foley J A, Defries R, Asner G P et al., 2005. Global consequences of land use. Science, 309(5734): 570-574.

Grashof-Bokdam C J, Cormont A, Polman N B P et al., 2016. Modelling shifts between mono- and multifunctional farming systems: The importance of social and economic drivers. Landscape Ecology, 32(3): 1-13.

Guo B, Jin X, Yang X et al., 2015. Determining the effects of land consolidation on the multifunctionlity of the 
cropland production system in China using a SPA-fuzzy assessment model. European Journal of Agronomy, 63: $12-26$.

Herdt R W, Mandac A M, 1981. Modern technology and economic efficiency of Philippine rice farmers. Economic Development and Cultural Change, 29(2): 375-399.

İlkay U G, Štefan B, 2015. Farm size and participation in agri-environmental measures: Farm-level evidence from Slovenia. Land Use Policy, 46: 273-282.

Jayne T S, Chamberlin J, Traub L et al., 2011. Africa's changing farm size distribution patterns: The rise of medium-scale farms. Agricultural Economics, 47(Suppl.1): 197-214.

Lambin E F, Meyfroidt P, 2011. Global land use change, economic globalization, and the looming land scarcity. Proceedings of the National Academy of sciences of the United States of America, 108: 3465-3472.

Liu J Y, Kuang W H, Zhang Z X et al., 2014. Spatiotemporal characteristics, patterns and causes of land use changes in China since the late 1980s. Journal of Geographical Sciences, 24(2): 195-210.

Liu Y, Song W, Deng X, 2016. Changes in crop type distribution in Zhangye City of the Heihe River Basin, China. Applied Geography, 76: 22-36.

Liu Y S, Fang C L, 2001. A study on regional forced land use conversion and optimal allocation: Taking the Three Gorges Reservoir Area as an example. Journal of Natural Resources, 16(4): 334-340. (in Chinese)

Long H L, Liu Y S, Li X B et al., 2010. Building new countryside in China: A geographical perspective. Land Use Policy, 27(2): 457-470.

Meng Q H, Fu B J, Yang L Z, 2010. Effects of land use on soil erosion and nutrient loss in the Three Gorges Reservoir Area, China. Soil Use \& Management, 17(4): 288-291.

Moran W, 1997. Farm size change in New Zealand. New Zealand Geographer, 53(1): 3-13.

Niroula G S, Thapa G B, 2005. Impacts and causes of land fragmentation, and lessons learned from land consolidation in South Asia. Land Use Policy, 22(4): 358-372.

Petit M, Weiss C, Heckelei T et al., 2011. Success in agricultural transformation: What it means and what makes it happen. European Review of Agricultural Economics, 39(5): 882-884.

Rgjr P, Schneider L C, 2001. Land-cover change model validation by an ROC method for the Ipswich watershed, Massachusetts, USA. Agriculture Ecosystems \& Environment, 85(1): 239-248.

Shao J A, Dang Y F, Wang W et al., 2018. Simulation of future land-use scenarios in the Three Gorges Reservoir Region under the effects of multiple factors. Journal of Geographical Sciences, 28(12): 1907-1932.

$\mathrm{Su}$ S, Zhou X, Wan C et al., 2016. Land use changes to cash crop plantations: Crop types, multilevel determinants and policy implications. Land Use Policy, 50: 379-389.

Tan M, Robinson G M, Li X et al., 2013. Spatial and temporal variability of farm size in China in context of rapid urbanization. Chinese Geographical Science, 23(5): 607-619.

Tang J Y, Zeng F S, 2014. The proper scale management of farmland: Types, performance and revelation: A case study of Hunan Province. Economic Geography, 34(5): 134-138. (in Chinese)

Wang J, Chen K Z, Gupta S D et al., 2015. Is small still beautiful? A comparative study of rice farm size and productivity in China and India. China Agricultural Economic Review, 7(3): 484-509.

Wang J F, Hu Y, 2012. Environmental health risk detection with GeogDetector. Environmental Modelling \& Software, 33(10): 114-115.

Wang J F, Li X H, Christakos G et al., 2010. Geographical detectors-based health risk assessment and its application in the neural tube defects study of the Heshun region, China. International Journal of Geographical Information Science, 24(1): 107-127.

Wang J F, Zhang T L, Fu B J, 2016. A measure of spatial stratified heterogeneity. Ecological Indicators, 67: $250-256$.

Wu G P, Zeng Y N, Xiao P F et al., 2010. Using autologistic spatial models to simulate the distribution of land-use patterns in Zhangjiajie, Hunan Province. Journal of Geographical Sciences, 20(2): 310-320.

$\mathrm{Xu}$ Q, Yin R L, 2010. Literature review on the issues of proper scale management of farmland in China. China Land Science, 24(4): 75-80. (in Chinese)

Yang P, Wang L, Zhang N et al., 2016. Family farms' scale at home and abroad. Chinese Agricultural Science Bulletin, 14: 200-204. (in Chinese)

Yang Q Y, Xin G X, Shi Y et al., 2009. Study on the scale of rural-land management in Chongqing. Journal of Southwest University (Natural Science Edition), 31(4): 143-147. (in Chinese)

You H, 2017. Agricultural landscape dynamics in response to economic transition: Comparisons between different spatial planning zones in Ningbo region, China. Land Use Policy, 61: 316-328.

Zhou Y, Tu J J, Lu D B et al., 2011. Study on the relationship between population and economic spatial distribution and its dynamic in Chongqing. Economic Geography, 31(11): 1781-1785. (in Chinese) 